\title{
ULTRASOUND-CATALYZED TEMPO-MEDIATED OXIDATION OF NATIVE CELLULOSE FOR THE PRODUCTION OF NANOCELLULOSE: EFFECT OF PROCESS VARIABLES
}

\author{
Shree P. Mishra, * Jennifer Thirree, Anne-S. Manent, Bruno Chabot, and \\ Claude Daneault
}

\begin{abstract}
In this study application of ultrasound in oxidizing native cellulose for the production of nanocellulose has been explored for the first time. Bleached hardwood kraft pulp was oxidized with an ultrasound (US) catalyzed 2,2,6,6-tetramethylepiperidin-1-oxyl (TEMPO) system (USTEMPO-system) at five different temperatures $-5,15,25,35$, and $45^{\circ} \mathrm{C}$ and two $\mathrm{pH}$ ranges, 8.5-9.0 and 10.0-10.5 - to obtain the optimum reaction conditions. The reaction $\mathrm{pH}$ and temperature have significant effect on the kinetics of the formation of carboxylate in the oxidized pulps and produce depolymerization at temperatures greater than $25^{\circ} \mathrm{C}$. Formation of carboxylate on the cellulose chain is directly proportional to the $\mathrm{NaBr}$ concentration. The pulp oxidized by the US-TEMPO-system at $25^{\circ} \mathrm{C}$ had $10-15 \%$ more carboxyls and showed a ca. $10 \%$ increase in the nanocellulose yield when compared to the TEMPO-system without sonocatalysis.
\end{abstract}

Keywords: Nanocellulose; TEMPO; Native cellulose; Oxidation; DPv; Carboxyl groups; Yield

Contact information: Centre de Recherche en Pâtes et Papiers (CRPP), 3351, Boulevard des Forges, Trois-Rivières (Québec) Canada G9A 5H7 *Corresponding author: Shree.Prakash.Mishra@uqtr.ca

\section{INTRODUCTION}

Native cellulose is mainly present in lignocellulosic biomass (wood and agriresidues). Besides being paracrystalline in morphology (Atalla 1987), native cellulose obtained from wood always contains varying amounts of other amorphous constituents, including hemicelluloses, and lignins, depending upon the refinement process. The hemicelluloses found in wood are mainly xyloglucan, arabinoxylans, and mannans, and the primary precursors for lignins are coniferyl alcohol, synapyl alcohol, and p-coumaryl alcohol. Principal steps for the isolation of cellulose from woody raw materials are digestion or cooking, and further purification or bleaching, involving complex chemical reactions using a range of chemicals. The bleached pulp so obtained forms the basis for the vast paper, board, textile, and other related industries world wide.

Undoubtedly, the paper industry is the biggest consumer of bleached, delignified pulp and will continue to be so in the future. Recent stagnant or sluggish performance of the pulp and paper industries (Brown 2010) throughout the world has speeded up the campaign to use the lignocellulosic biomass for producing value-added products. Besides the biorefinery concept, which is one of the most sought-after projects (Cherubini 2010; Kamm and Kamm 2007; Luo et al. 2010), production of cellulose nanofibers from native cellulose has also been the subject of intensive investigation (Habibi and Dufresne 2008; 
Henriksson and Berglund 2007; Iwamoto et al. 2005, 2007; Janardhnan and Sain 2006; Nakagaito and Yano 2004; Paakko et al. 2007; Saito et al. 2005, 2006a,b; Taniguchi and Okamura 1998; Wang and Sain 2007). Fundamentally, lignocellulosic biomass is made up of nanometer-scale cellulose building blocks that provide valuable properties (mechanical, optical, and other) to wood and other types of renewable lignocellulosic and cellulosic biomaterials. Similarly, the nanometer dimensions of the cellulose, lignin, and other components provide the origin for the unique properties of wood, in addition to a host of wood-based products including paper, paperboard, oriented strandboard, glulam beams, etc., (Klemm et al. 2005). These nanosized cellulose building blocks, which are networked, and irreversibly fixed in the supramolecular cellulose structure, and determines the product properties and functionality, have been described as nanocellulose (Klemm et al. 2005). While the relative mass of the nanofibrils and nanocrystalline cellulose are small, their surface area is large (Wegner and Jones 2009).

Cellulose nanofibers can be prepared by various ways and often bear different names such as "whiskers" (de Rodriguez et al. 2006; Oksman et al. 2006; Rånby 1952; Samir et al. 2005), "microfibrillar cellulose," (MFC) (Stenstad et al. 2008), and "nanofibrillar cellulose," (NFC) (Paakko et al. 2008). "Whiskers," which are also called "nanorods," "rod-like cellulose microcrystals," or "nanowires," are very long and straight crystals of cellulose, whereas MFCs and NFCs remain attached together for at least a portion of their length (Hubbe et al. 2008).

During the last few years efforts have been made to prepare cellulose nanofibers or nanocellulose from native cellulose by TEMPO-mediated oxidation using a TEMPO$\mathrm{NaBr}-\mathrm{NaOCl}$ system followed by mechanical treatment or with the help of ultrasonic waves (Johnson et al. 1999; Saito and Isogai 2005; Saito et al. 2007). The term TEMPO stands for 2,2,6,6-tetramethylpiperidin-1-oxyl. Oxidation of the primary alcohol groups (C6 hydroxyls in the cellulose chain) in the presence of secondary and tertiary hydroxyls to carboxylate is the main objective of TEMPO-NaBr- $\mathrm{NaOCl}$ treatments (de Nooy et al. 1995). Such regioselective conversion of the primary hydroxyl groups to carboxylate will make it possible to loosen the adhesion between cellulose fibrils by preventing the formation of strong interfibril hydrogen bonds (Saito et al. 2007). A general reaction scheme of the oxidation of C6 hydroxyl to the carboxyl group by TEMPO-system is shown in Fig. 1. The detailed reaction mechanism has been described in Li (2006).
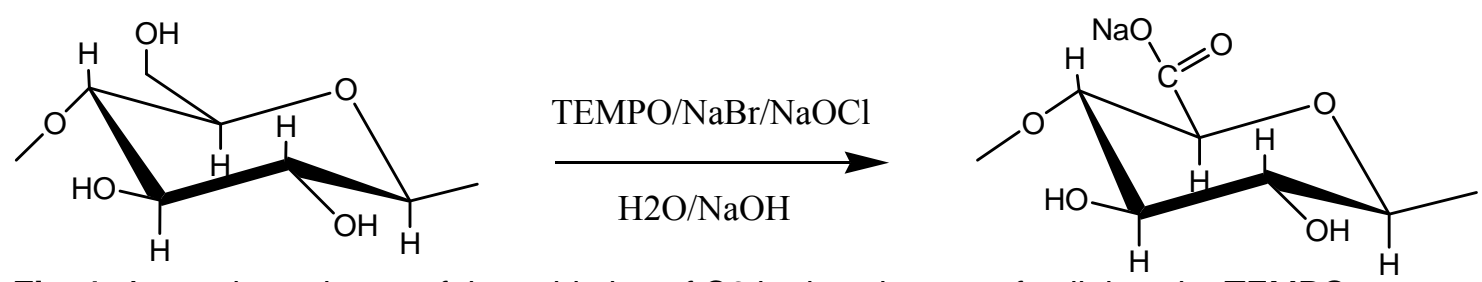

Fig. 1. A reaction scheme of the oxidation of $\mathrm{C} 6$ hydroxyl group of cellulose by TEMPO-system

The dimensions (width and length) of the cellulose nanofibers or nanocelluloses obtained by TEMPO mediated oxidation followed by mechanical treatment have been measured with transmission electron microscope (TEM). TEM is the most commonly used technique for the determination of the dimensions of the cellulose nanofibers. The widths of the nanocelluloses were in the range of 3 to $5 \mathrm{~nm}$, and their lengths varied from 
nanometers to a few microns (Saito et al. 2007). However, the geometrical dimensions of the cellulose nanocrystals (obtained by acid hydrolysis) vary widely depending on the source of the cellulosic material, the hydrolysis conditions, and on the measurement techniques used (Habibi et al. 2010).

The use of ultrasound for catalyzing chemical reactions has already been documented (Kardos and Luche 2001; Suslick 1995; Suslick and Price 1999). Several carbohydrate compounds have also been subjected to ultrasound-catalyzed oxidation (Kardos and Luche 2001; Zhang et al. 2008). Some studies have shown the effect of ultrasound on pulp preparation (fibrillation) (Iwasaki et al. 1962), and deinking of printed papers (Manning 2004), However, no chemical changes on the cellulose chain due to ultrasound have been reported so far (Thompson and Manning 2005). In liquid phase reaction medium, high intensity ultrasound waves function through the mechanism of acoustic cavitation (the formation, growth, and collapse of bubbles) (Leighton 1994) and consequently lead to a sonochemical effect. During cavitation, the bubbles collapsing produce intense local heating and high pressure for a very short lifespan. These transient, localized hot spots drive high energy chemical reactions, yielding temperatures of $\sim 5000^{\circ} \mathrm{C}$, pressures of about $1000 \mathrm{~atm}$, and heating and cooling rates above $10^{10} \mathrm{~K} / \mathrm{s}$ (Suslick 1990; Suslick and Price 1999). An extensively studied reaction is the sonolysis of water, producing hydroxyl radicals and hydrogen atoms (Henglein and Kormann 1985).

$$
\begin{gathered}
\mathrm{H}_{2} \mathrm{O} \rightarrow \mathrm{H} \bullet+\mathrm{HO} \bullet \\
\mathrm{HO} \bullet+\mathrm{HO} \bullet \rightarrow \mathrm{H}_{2} \mathrm{O}_{2} \\
\mathrm{H} \bullet+\mathrm{O} 2 \rightarrow \mathrm{HO}_{2} \bullet
\end{gathered}
$$

The aim of this study was to use high-intensity ultrasound in combination with a TEMPO system to oxidize the primary hydroxyl groups on the cellulose polymer chains to carboxylate groups. We used high intensity ultrasonic waves at $68 \mathrm{kHz}$ and $170 \mathrm{kHz}$ frequencies along with the TEMPO system for the oxidation of once-dried bleached hardwood kraft pulp at various temperatures, and at different amounts of sodium bromide. We attempted to explain the correlation between the $\mathrm{NaOH}$ consumption, and the final $\mathrm{pH}$ to assess the extent of oxidation of the cellulose fibers. Cellulose nanofibers obtained from selected samples of different carboxylate contents using mechanical treatment were quantified gravimetrically.

\section{EXPERIMENTAL}

\section{Materials}

A mill-bleached, machine-dried hardwood kraft pulp was used as a source of native cellulose for the oxidation purpose. 4-acetamido-TEMPO $(2,2,6,6$ tetramethylpiperidin-1-oxyl), sodium bromide $(\mathrm{NaBr})$, and sodium chlorite $\left(\mathrm{NaClO}_{2}\right)$ were obtained from Sigma-Aldrich and used as received. Sodium hypochlorite $(\mathrm{NaOCl})$ was procured locally, and assayed for its molar concentration before use. The ultrasonic cleaning bath and ultrasonic generators were procured from Ultrasonic Power Corporation (USA). Two different ultrasonic generators were used to produce $68 \mathrm{kHz}$ 
and $170 \mathrm{kHz}$ frequency ultrasonic waves. These were operated at 500, 750, and $1000 \mathrm{~W}$ ultrasonic power intensity. The cleaning bath was set at both frequencies.

\section{Methods}

Pulp oxidation by US (ultrasound)-TEMPO-NaBr-NaOCl-system

Oxidation of bleached hardwood kraft pulp was carried out batchwise using $20 \mathrm{~g}$ (wt. \%) sample per batch. The pulp was pre-soaked overnight in de-ionized water, and disintegrated for 10 minutes in a laboratory disintegrator to obtain a uniform fiber suspension of about 1\% consistency. The oxidation was conducted in a specially designed glass reactor that was placed in an ultrasonic cleaning bath to ensure that it was exposed to a uniform ultrasound effect. The frequencies of the ultrasonic waves used were $68 \mathrm{kHz}$, and $170 \mathrm{kHz}$ at $1000 \mathrm{~W}$ ultrasonic power intensity unless otherwise mentioned. 4-acetamido TEMPO (0.46 g, $0.11 \mathrm{mmol}$ per g cellulose fiber), and $\mathrm{NaBr}$ $(1.27 \mathrm{~g}, 0.617 \mathrm{mmol}$ per g cellulose fiber) were dissolved in $50 \mathrm{~mL}$ of de-ionized water before being added to the fiber suspension. The $\mathrm{pH}$ of the fiber slurry was adjusted to 10.0-10.2 with $0.5 \mathrm{M} \mathrm{NaOH}$ or $0.5 \mathrm{M} \mathrm{HCl}$ using a $\mathrm{pH}$-stat as required. The TEMPOmediated oxidation was started by adding the desired amount of the $\mathrm{NaOCl}$ solution $(3.75$ mmol NaOCl per $\mathrm{g}$ of cellulose fiber), at $25^{\circ} \mathrm{C}$. Deviations related to chemical charges are specified in the respective sections. The $\mathrm{pH}$ was maintained at 10.0 to 10.2 by adding $0.5 \mathrm{M} \mathrm{NaOH}$ using a pH-stat during the course of the reaction, and the amount of $\mathrm{NaOH}$ consumed was noted at 15-minute intervals. The reaction was stopped after 90 minutes by adding $50 \mathrm{~mL}$ of ethanol, and the final $\mathrm{pH}$ of the solution was adjusted to 7.0 by adding $0.5 \mathrm{M} \mathrm{NaOH}$ or $0.5 \mathrm{M} \mathrm{HCl}$ as required. The total volume of the TEMPO-oxidized fiber suspension was measured, and a known volume of which was filtered and washed with de-ionized water on a pre-weighed filter paper to quantify the yield after oxidation. The rest of the TEMPO-oxidized cellulose slurry was filtered, thoroughly washed with de-ionized water, and stored at $4{ }^{\circ} \mathrm{C}$ (to prevent from any kind of microbial attack) for further treatment, and analysis. Similar TEMPO-mediated oxidations were performed in the absence of ultrasonic waves. A photograph of the experimental setup for the USTEMPO-system is shown in Fig. 2.

\section{Measurement of carboxyl group content}

The carboxylate content of the TEMPO-oxidized cellulose was determined using a conductometric titration method using a Dosimat 765 (Metrohm) titrator according to the technique of Katz et al. (1984). The sodium carboxylate groups in the TEMPOoxidized celluloses were converted to the free carboxyl form by treating the sample with $0.1 \mathrm{M} \mathrm{HCl}$ solution three times and finally, thoroughly washed with de-ionized water to remove the excess acid. The oxidized pulp prepared in this way was transferred to a 600$\mathrm{mL}$ beaker containing $450 \mathrm{~mL}$ of $0.001 \mathrm{~N} \mathrm{NaCl}$ solution, and mixed well. Five $\mathrm{mL}$ of 0.1 $\mathrm{N} \mathrm{HCl}$ was added to the fiber suspension before starting the titration of carboxylate groups with $0.1 \mathrm{~N} \mathrm{NaOH}$ solution. The titration was controlled by use of automatic titration software developed in our institute. At the end of the titration the fibers were filtered, washed, and dried in an oven at $105{ }^{\circ} \mathrm{C}$ to determine the exact weight of the sample. The carboxyl content expressed in $\mathrm{mmol} / \mathrm{kg}$ was calculated by the software. 


\section{Post-oxidation of the oxidized pulp}

A post oxidation of the oxidized pulp with $\mathrm{NaClO}_{2}$ in acetic acid / sodium hydroxide buffer (pH 5.0) at $70{ }^{\circ} \mathrm{C}$ was done to convert the aldehyde groups produced during the TEMPO-mediated oxidation of cellulose to carboxyl groups. In this process 2 $\mathrm{g}$ of the oxidized pulp (WT. \%) was suspended in $160 \mathrm{~mL}$ of deionised water in a tightly closed 250-mL glass bottle (from Duran). This was followed by the addition and mixing, sequentially, of $20 \mathrm{~mL}$ of $34 \mathrm{~g} / \mathrm{L} \mathrm{NaClO}_{2}$ solution and $20 \mathrm{~mL}$ of acetic acid/ sodium hydroxide buffer. The mixture was kept in a water bath at $70{ }^{\circ} \mathrm{C}$ for $2 \mathrm{~h}$, after which it was cooled, filtered and washed thoroughly with water prior to further analysis. This method gave results similar to those yielded by the technique of Saito and Isogai (2004), and hence it was used in this work.

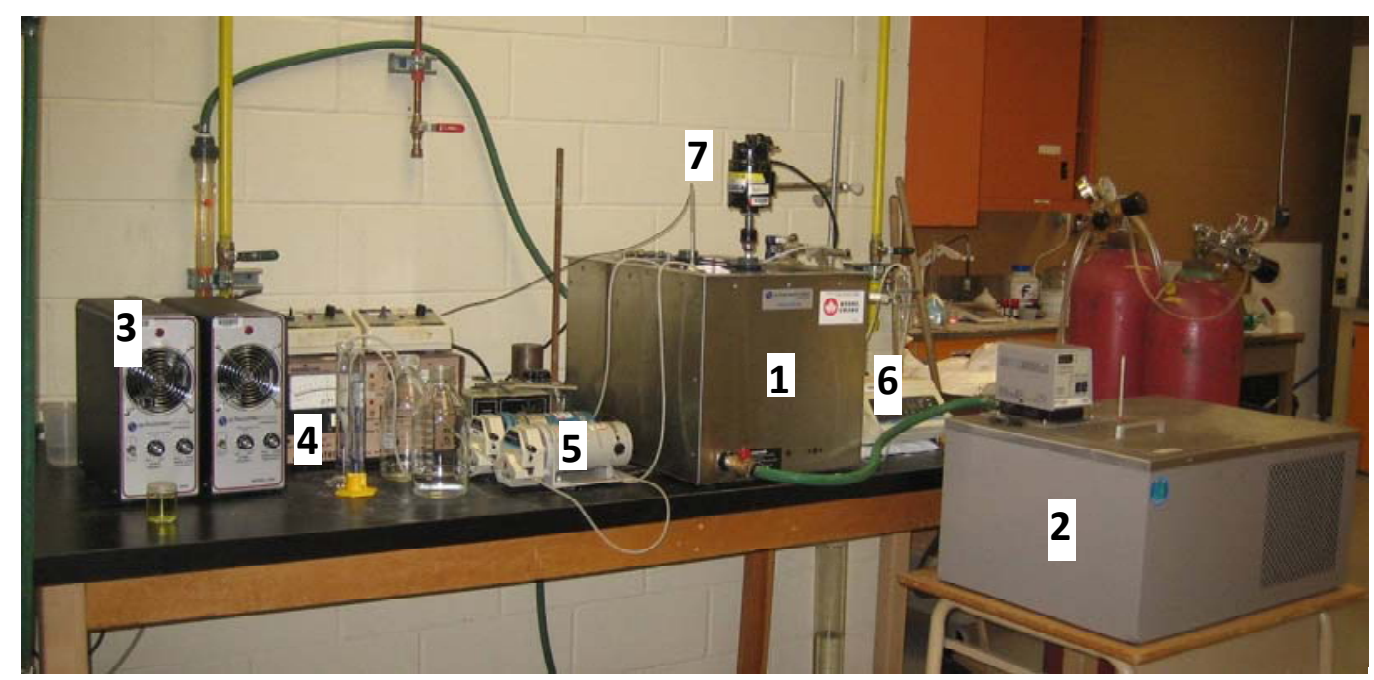

1. Ultrasonic bath

2. Thermostated bath for cooling

3. Ultrasonic generators

4. $\mathrm{pH}$ controller

5. Peristaltic pumps for $\mathrm{NaOH}$ and $\mathrm{HCl}$

6. Peristaltic pump for $\mathrm{NaOCl}$

7. Motor for the agitator

8. Reactor for the oxidation

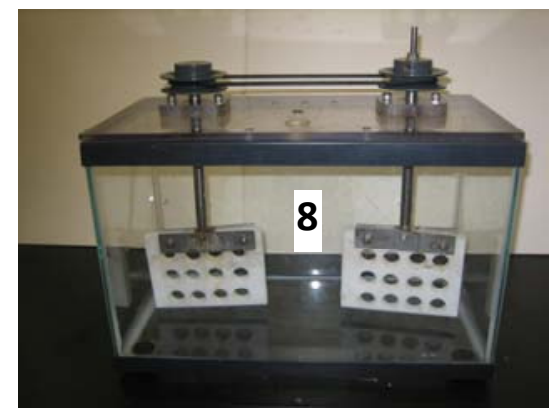

Fig. 2. Photograph of the experimental setup for the oxidation with TEMPO-, and US-TEMPOsystems

\section{Measurement of viscosity}

The relative viscosity of the TEMPO- and US-TEMPO-oxidized celluloses, as well as reference samples was measured as per SCAN standard methods SCAN-CM 15:88. The degree of polymerization (DPv) was calculated as per the Sihtola method, using the following Mark-Houwink-Sakurada equation: $\mathrm{DPv}^{0.905}=0.75$ [ $]$ (Sihtola and Kyrklund 1963). The DPv calculation is based on the assumption that both cellulose and oxidized cellulose molecules have the same viscosity at the same DP. 


\section{NMR Measurements}

Solid-state $\mathrm{CP} / \mathrm{MAS}{ }^{13} \mathrm{C}$ spectra were recorded on a Bruker Advance Spectrometer (Bruker Biospin Inc, Milton, ON, Canada) at 75 or $100 \mathrm{MHz}$ (Magnetic fields of 7.0 or 9.4 Tesla). Samples were spun at 6 to $8 \mathrm{kHz}$ in a $4 \mathrm{~mm} \mathrm{ZrO}_{2}$ rotor at the magic angle, and at room temperature. A contact time of $1 \mathrm{~ms}$, and a relaxation time of 1 s were accorded to an acquisition of 3000 transients to produce a good quality spectrum. A high power phase altered proton decoupling time-proportional-phase-increment (TPPI) was applied during free induction decay (FID) acquisition. ${ }^{13} \mathrm{C}$ chemical shifts were determined with reference to adamantane.

\section{Production of nanocellulose}

The oxidized cellulose sample $(0.3 \mathrm{~g})$ was suspended in water $(300 \mathrm{~mL})$ at $0.1 \%$ concentration. The slurry was mechanically homogenized by means of a blender for a total time of $20 \mathrm{~min}$ (Saito et al. 2007). A pause of $15 \mathrm{~s}$ followed after each $45 \mathrm{~s}$ of mixing to prevent overheating of the blender. The disintegrated suspension was centrifuged at $10,000 \mathrm{~g}$ during $10 \mathrm{~min}$ to separate the supernatant containing nanocellulose from the unfibrillated and partially fibrillated fractions. The quantity of nanocelluloses was obtained by drying three samples of $40 \mathrm{~mL}$ each from the supernatant at $105^{\circ} \mathrm{C}$. The slurry was stored at $4^{\circ} \mathrm{C}$ (to prevent from any kind of microbial attack) for further characterization.

\section{TEM observation}

The samples were examined using a Phillips EM 208S transmission electron microscope (TEM) operating at $80 \mathrm{kV}$. Images were acquired electronically with an installed camera. Diluted nanofibril suspensions were deposited on the formvar-coated copper grids (400 mesh). The excess liquid was absorbed with filter paper, and the adsorbed nanofibers were stained with $2 \%$ uranyl acetate negative stain before observation with TEM.

\section{RESULTS AND DISCUSSION}

This study was carried out with mill-produced bleached hardwood kraft pulp as a source of native cellulose. First of all, the pulp was subjected to an ultrasound (US) treatment under similar conditions as to the regular experiments using the US (ultrasound)-TEMPO system to determine its effect on the cellulose fibers, especially on the carboxyl groups. The carboxyl group content, yield, and viscosity obtained with US alone at $68 \mathrm{kHz}$ and $170 \mathrm{kHz}$ without the TEMPO-system are shown in Table 1. No change in the carboxyl group content was found when the oxidation was carried out with US alone without using TEMPO-system compared to the reference pulp, which confirms the previous findings on the subject (Thompson and Manning 2005). The degree of polymerization (DPv), and yield of the US treated pulps were not much affected. Better yield, and DPv were obtained at $170 \mathrm{kHz}$ as compared to $68 \mathrm{kHz}$ (Table 1). The carboxyl group content after post-oxidation was comparable to that of the reference pulp. 
However, the use of ultrasound along with the TEMPO-system for the oxidation of pulp produced different results, which are presented in the following paragraphs.

Table 1. Effect of Ultrasonic Treatment on the Carboxyl Group Content, Yield, and DPv of the Pulp

\begin{tabular}{|l|c|c|c|c|}
\hline \multicolumn{1}{|c|}{ Parameter } & COO- $(\mathrm{mmol} / \mathrm{kg})$ & $\begin{array}{c}\text { COO- Post-Oxidation } \\
(\mathrm{mmol} / \mathrm{kg})\end{array}$ & Yield (\%) & DPv \\
\hline Bleached pulp & $61.1(60.7,61.4)$ & $70.8(72.7,68.9)$ & 100 & 997 \\
\hline PB - US $68 \mathrm{kHz}\left(25^{\circ} \mathrm{C}\right)$ & $60.4(62.7,58.1)$ & $71.8(77.8,65.7)$ & 96.4 & 936 \\
\hline PB - US $170 \mathrm{kHz}\left(25^{\circ} \mathrm{C}\right)$ & $61.2(60.1,62.2)$ & $66.3(66.6,66.0)$ & 98.8 & 981 \\
\hline
\end{tabular}

\section{Effect of Temperature (US-TEMPO-system)}

It is well known that in aqueous medium ultrasound functions according to the principle of acoustic cavitation, which generates a lot of heat that could reach up to several degrees centigrade (Suslick and Price 1999). One may think that the extra heat generated during the US treatment may increase the rate of the reaction if the temperature of the reaction is not maintained. Our experiments were done at $5,15,25,35$ and $45^{\circ} \mathrm{C}$, while keeping the other conditions constant, to find out the effect of the temperature on the reaction kinetics and advantages of using ultrasound in TEMPO- oxidation system. It should be noted that a lot of ice was needed to maintain the temperature during the US run. In fact, we were not able to conduct the US treatment at $5^{\circ} \mathrm{C}$ and, therefore, the oxidation of the pulp at $5^{\circ} \mathrm{C}$ was carried out in the absence of US treatment. The carboxyl group content, yield, and DPv of the oxidized pulp are plotted as a function of temperature, as shown in Figs. 3 through 5.

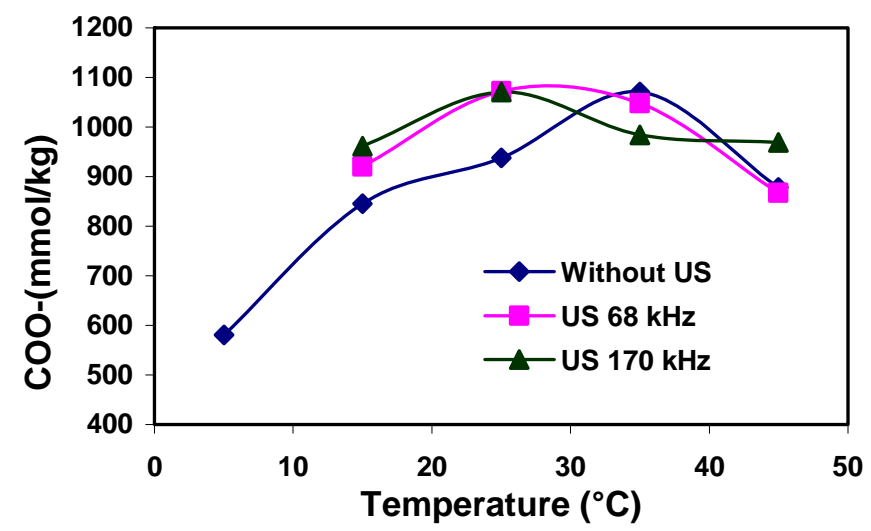

Fig. 3. Effect of temperature on the carboxyl group content in the US-TEMPO-system oxidized pulp

The carboxyl groups content increased with the increase in temperature up to $25^{\circ} \mathrm{C}$, and it started to decrease at $35^{\circ} \mathrm{C}$ onwards in the case of US treatments, whereas without US it increased up to $35^{\circ} \mathrm{C}$ and then decreased. Figure 3 shows that a gain of about $15 \%$ was obtained with the presence of US treatment, i.e. $1071 \mathrm{mmol} / \mathrm{kg}$ versus $938 \mathrm{mmol} / \mathrm{kg}$ for TEMPO alone, at $25^{\circ} \mathrm{C}$. The decrease in carboxyl group content at temperatures $>25^{\circ} \mathrm{C}$ in US-TEMPO oxidation and $>35^{\circ} \mathrm{C}$ in TEMPO alone could be 
related to the de-polymerization and simultaneous dissolution of the carboxylatecontaining sugar moieties during the oxidation reaction, leading to a loss in yield. It could be seen from Fig. 4 that the yield after oxidation was less than $85 \%$ in all the samples at $45^{\circ} \mathrm{C}$.

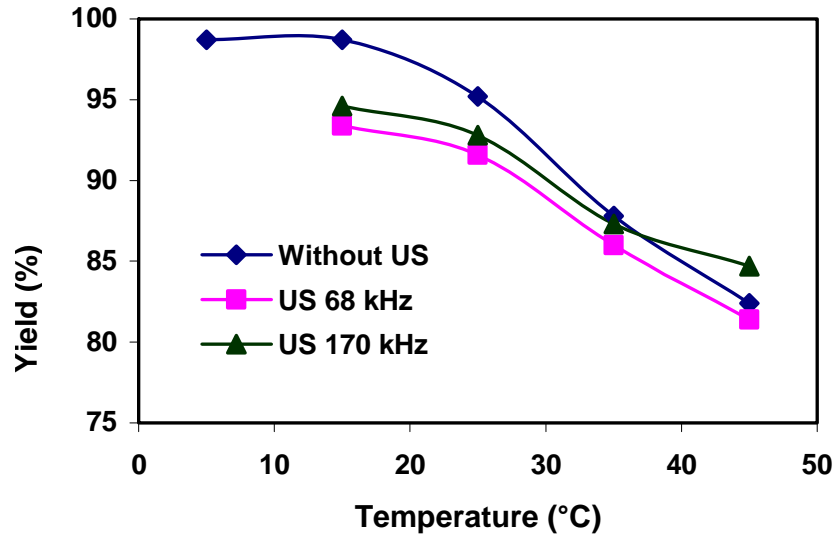

Fig. 4. Effect of temperature on the yield of the US-TEMPO-system oxidized pulp

Figure 4 shows that the yield decreased with increasing temperature in all the cases. Again, one reason could be the depolymerization of the cellulose and dissolution of the oxidized moieties with increase in the temperature, as mentioned above. Another possible reason could be the dissolution of the amorphous, non-cellulosic pulp constituents (hemicelluloses, pectins, and lignins) during the course of the US-TEMPOmediated oxidation, in addition to the possibility that dissolution was further aggravated at higher temperatures. Isogai and Kato (1998) have also shown that the charge of TEMPO, reaction time, and temperature were the key factors controlling the depolymerization of cellulose in the case of TEMPO-mediated oxidation of regenerated or mercerized cellulose. At a given temperature the yield loss was more pronounced in the case of ultrasonic treatments as compared to the cases where no US treatment was involved. Note that the US treatment at $68 \mathrm{kHz}$ gave lower yield than that at $170 \mathrm{kHz}$. One possible explanation for the greater loss in yield with US-TEMPO-system could be that the collapse of cavitation bubbles, the principal mechanism involved in the sonochemistry, in the reaction medium with the presence of oxidants facilitated the access of the reactive species to the reaction site with a greater ease increasing the reaction rate and yielded the related effects. However, simultaneous detachment and dissolution of the oxidized nanofibrils due to turbulent mixing and jets-streaming, a resultant effect of acoustic cavitation, might have led to the yield loss. The fact that cavitation effects are significant at lower US frequencies may be one reason for the observed greater yield loss at $68 \mathrm{kHz}$. From another viewpoint the observed effects of the ultrasound with the TEMPO-system could, possibly, be explained as follows: TEMPOmediated oxidation of solid-state cellulose involves a great deal of difficulty in the separation of cellulose nanofibrils that strongly interact with each other via multiple hydrogen bonding. Thus, the ultrasonication is expected to have some contribution to loosening the cellulose nanofibrils, and to peeling the slightly carboxylated cellulose 
chains/nanofibers from the solid cellulose sample. Considering the high carboxyl group content of $1071 \mathrm{mmol} / \mathrm{kg}$ and good yield of $93 \%$ obtained at $25^{\circ} \mathrm{C}$, this temperature was found satisfactory in comparison to other temperatures studied.

The DPv of the pulps was considerably affected during the US-TEMPO and TEMPO mediated oxidation. The observed DPv of the oxidized pulps was about four times less compared to the DPv of the original pulp. The DPv of the oxidized pulps were in the range of 200-250 (Fig. 5), whereas the DPv of the original pulps without TEMPO oxidation was in the range of 900 to 1000 (Table 1). The DPv of the US-TEMPO and TEMPO oxidized pulps decreased with increase in the temperature (Fig. 5); however, at a given temperature there was no significant difference in the DPv of the pulps oxidized with US-TEMPO and TEMPO system. The depolymerization of polysaccharides having glucuronic acid may occur to some extent by $\beta$-elimination during the TEMPO-mediated oxidation under alkaline conditions, e.g. $\mathrm{pH} 10.0$ here (Kitaoka et al. 1999). However, besides the above mentioned reason, the depolymerization of the cellulose has also been attributed to the sodium hypochlorite oxidation of polysaccharides, leading to 2,3scission of glucose units resulting in the formation of aldehyde and dicarboxylic structures (Besemer 1993).

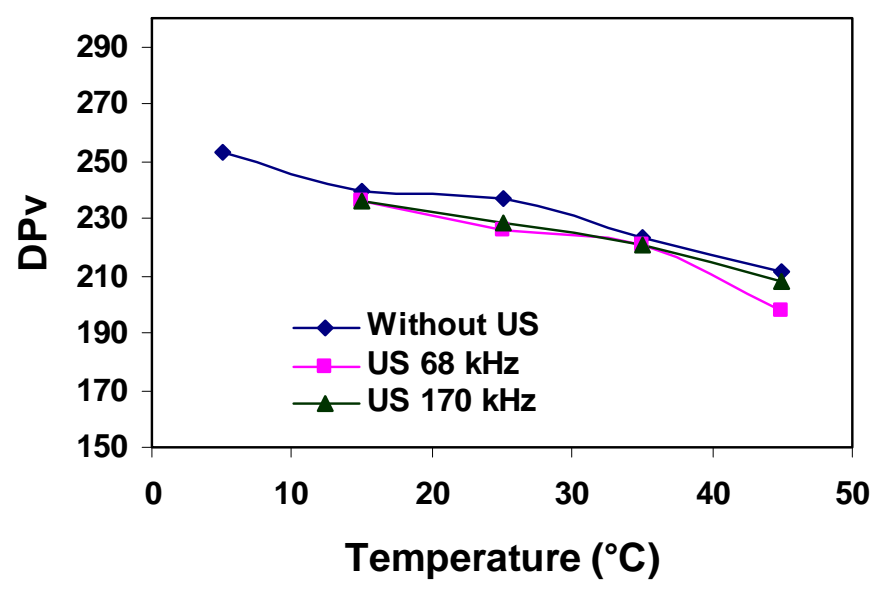

Fig. 5. Effect of temperature on the DPV of US-TEMPO-system oxidized pulp

\section{Aldehyde content at different temperatures}

The oxidation of the C6 hydroxyls to carboxyl group proceeds through an intermediate aldehyde group (Bragd et al. 2004; de Nooy et al. 1995). The oxidation is seldom complete, and some amount of the aldehyde remains in the pulp, which could have a considerable influence on the behavior of the oxidized pulp (Saito and Isogai 2004). Aldehyde groups in the oxidized pulps were determined following an indirect method by which the aldehyde groups were converted to carboxylate by post-oxidation with $\mathrm{NaClO}_{2}$ in acetate buffer at $\mathrm{pH}$ 5. The carboxyl group content in the post-treated pulp was re-determined. The difference in carboxyl contents before and after post oxidation was taken as a measure of the aldehyde groups present in the oxidized pulp. 


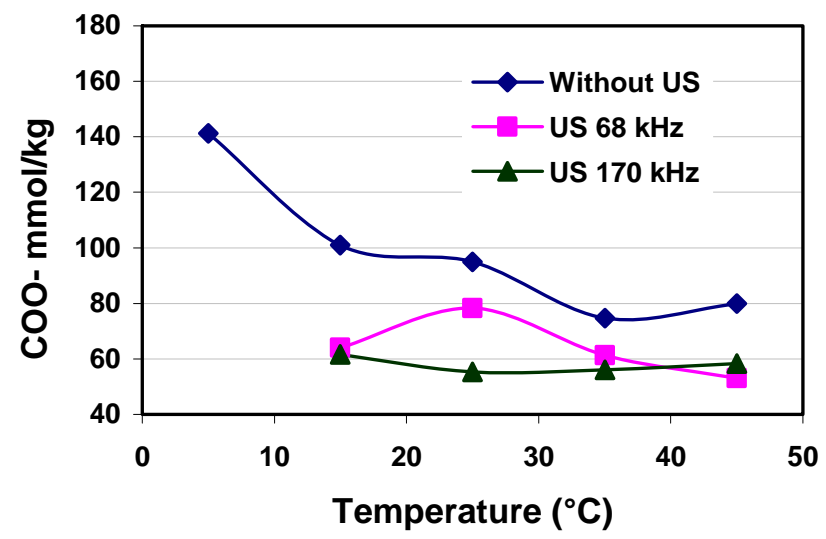

Fig. 6. Carboxyl group content (post oxidation - pre oxidation) as a measure of aldehyde content as a function of temperature

The aldehyde contents of the pulps oxidized with US-TEMPO-system at different temperatures are presented in Fig. 6. The aldehyde contents ranged from 50 to 100 $\mathrm{mmol} / \mathrm{kg}$ of pulp. It could be observed that with increase in the reaction temperature, oxidation with TEMPO system proceeded towards completion, and lesser amounts of the aldehyde groups were formed. An exception was noted in the case where the pulp was oxidized at $5^{\circ} \mathrm{C}$ and yielded a high aldehyde content of $140 \mathrm{mmol} / \mathrm{kg}$. Incomplete conversion of the aldehydes formed during the TEMPO-mediated oxidation reaction to carboxyls because of the lower temperature and shorter reaction times could be the possible reason for this phenomenon. From the results in Fig. 6, we can say that the USTEMPO oxidation system, which gave less aldehyde content, was more efficient than the TEMPO oxidation system without US treatment.

The DPv calculated based on the viscosity of the pulp after post-oxidation increased by about two-fold when the oxidation was performed at 5,15 , and $25^{\circ} \mathrm{C}$ in comparison with the DPv of the oxidized pulp samples before post-oxidation (Fig. 7). A possible reason to this effect could be the presence of aldehyde groups generated during the oxidation process, which may have rendered the cellulose polymers vulnerable to depolymerization in the highly alkaline CED solution used for the viscosity determination. A post-oxidation treatment converted the aldehyde groups to carboxyls and thus eliminated any kind of possible damage due to the highly alkaline conditions during CED viscosity measurement. Celluloses containing carbonyl groups have been found to be depolymerised by CED solution during the viscosity measurement $(\beta$ elimination) (Chandra and Gratzl 1985; de Nooy et al. 1996; Godsay and Pearce 1984; Isogai and Kato 1998). This undesirable effect occurred in addition to the cellulose depolymerization caused by sodium hypochlorite during the TEMPO-mediated oxidation. It has also been shown that the carbonyl groups on polysaccharides could lead to alkaliinduced $\beta$-alkoxy elimination reactions (Calvini et al. 2004; Gratzl 1987; Gratzl 1990; Samuelson 1970; Theander 1975). The $\beta$-elimination causes chain rupture, decreasing the pulp viscosity and hence the DPv. The increase in DPv after post-oxidation was less pronounced when the pulps were oxidized at higher temperatures such as 35 and $45^{\circ} \mathrm{C}$. This phenomenon could be attributed to the fact that at higher temperatures $\left(\right.$ e.g. $\left.>35^{\circ} \mathrm{C}\right)$ 
the pulp underwent substantial depolymerization, damaging considerably the intrinsic strength of the cellulose polymer and thus leading to the loss in DP and dissolution of the oxidized fraction. Hence the DPv of the oxidized pulp could not be restored to the same extent as was observed in the case of pulps oxidized with US-TEMPO or TEMPO-system at temperatures less than or equal to $25^{\circ} \mathrm{C}$. Elimination or conversion of the aldehyde groups either by reduction back to the hydroxyl groups with sodium borohydride (Chirat et al. 1993; Du Manoir 1980) or by oxidation to carboxyls with sodium chlorite as found in this study could be an efficient way to reduce the risk of further depolymerisation of the oxidized pulp during the viscosity measurement using CED solution. If we neglect the other unknown reactions, alkali-induced $\beta$-elimination reactions due to aldehyde groups may be one possible reason for such depolymerisations, as only carbonyl groups were concerned during the post-oxidation with sodium chlorite. Thus, the DPv of the pulp after post-oxidation can be considered as close to the true DP of the TEMPO oxidized pulps with CED method.

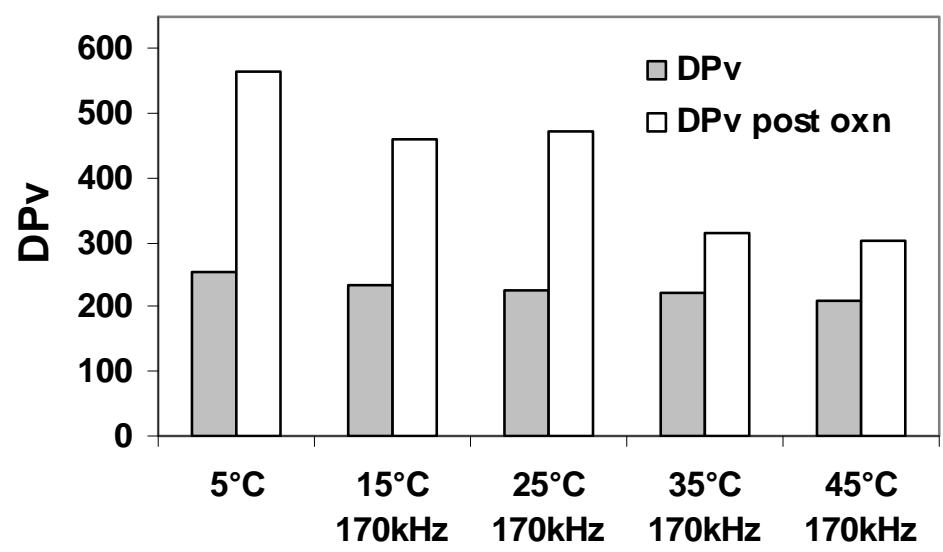

Fig. 7. DPv before and after post oxidation of the US-TEMPO (170 kHz), and TEMPO oxidized pulps at various temperatures

\section{Trend of NaOH consumption in US-TEMPO-system at different temperatures}

The trend of the $\mathrm{NaOH}$ consumption versus time at all the temperatures studied is shown in Fig. 8. One of the major observations during the oxidation with US-TEMPOsystem and TEMPO-system was the consumption of the $\mathrm{NaOH}$, and the final $\mathrm{pH}$ after stopping the reaction with ethanol at the end of the reaction time. It was found that the consumption of $\mathrm{NaOH}$ increased gradually during the reaction. At a given point of time the consumption of the $\mathrm{NaOH}$ was more significant in the case of US-TEMPO-system compared to TEMPO-system alone, which provides indirect evidence of the efficacy of the US-TEMPO-system. At all the temperatures studied the consumption of $\mathrm{NaOH}$ was apparently higher, in most of the cases, when oxidation was carried out with USTEMPO-system at $170 \mathrm{kHz}$ compared to US-TEMPO-system at $68 \mathrm{kHz}$ and TEMPO alone without US. This would mean that US-TEMPO-system with high frequency ultrasound is more efficient in oxidizing native cellulose compared to one with the lower frequency at the same intensities. 

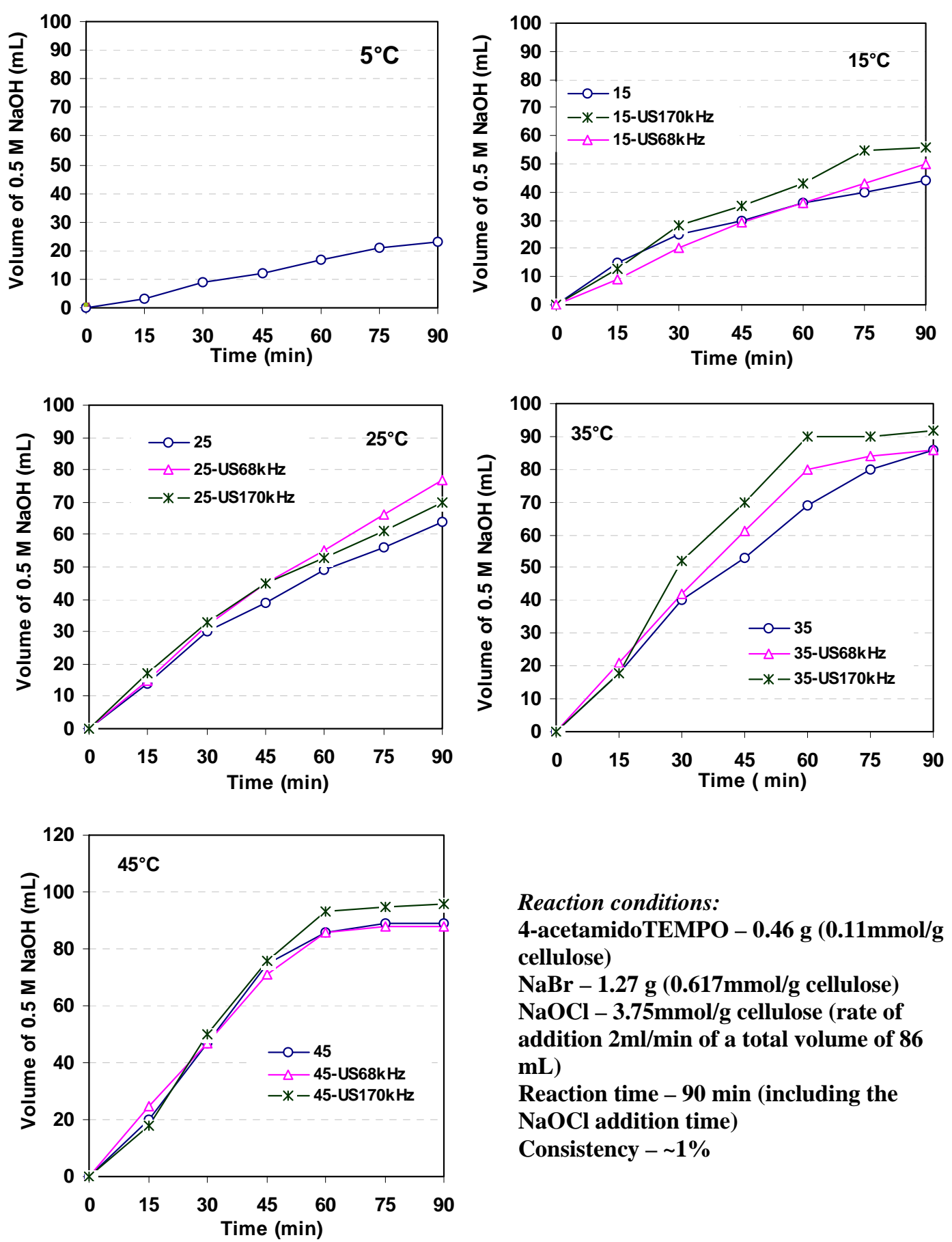

Reaction conditions: 4-acetamidoTEMPO - 0.46 g (0.11 mmol/g cellulose)

$\mathrm{NaBr}-1.27 \mathrm{~g}(\mathbf{0 . 6 1 7} \mathrm{mmol} / \mathrm{g}$ cellulose $)$ $\mathrm{NaOCl}-3.75 \mathrm{mmol} / \mathrm{g}$ cellulose (rate of addition $2 \mathrm{ml} / \mathrm{min}$ of a total volume of 86 mL)

Reaction time - 90 min (including the $\mathrm{NaOCl}$ addition time)

Consistency - 1\%

Fig. 8. Consumption of $0.5 \mathrm{M} \mathrm{NaOH}$ solution versus reaction time at various temperatures

Several conclusions could be drawn from the results shown in Figs. 8 and 9. First, at a given temperature the $\mathrm{NaOH}$ consumption, which can be considered as an indication of the extent of carboxylate formation on the $\mathrm{C} 6$ carbons, a faster reaction occurred in the case of oxidations with US-TEMPO-system compared to TEMPO-system alone. The $\mathrm{NaOH}$ was consumed during the oxidation in order to neutralize the generated carboxylic 
acid groups and to maintain the reaction $\mathrm{pH}$ 10.0. However, when the oxidation was conducted at $45^{\circ} \mathrm{C}$, the kinetics was mainly driven by the temperature. Second, after a certain time the consumption of $\mathrm{NaOH}$ stopped, remaining nearly constant for the rest of the reaction time. This indicates the complete consumption of $\mathrm{NaOCl}$ during the reaction; i.e. $\mathrm{NaOCl}$ became limiting in this particular case. The consumption of $\mathrm{NaOH}$ was stagnant when the oxidation was carried out at $35^{\circ} \mathrm{C}$ with $170 \mathrm{kHz}$ or at $45^{\circ} \mathrm{C}$ after about $90 \mathrm{~mL}$ of $0.5 \mathrm{M} \mathrm{NaOH}$. In such cases the reaction could be stopped after 60 minutes instead of 90 minutes because all the available sodium hypochlorite was consumed within 60 minutes.



Fig. 9. Final $\mathrm{pH}$ versus temperature of the pulp suspension after stopping the oxidation reaction with $\mathrm{EtOH}$ )

Third, the oxidation reaction was complete at 35 and $45^{\circ} \mathrm{C}$ in all the cases. It was nearly completed at $25^{\circ} \mathrm{C}$ when the US treatments were applied under the given experimental conditions (observed final $\mathrm{pH} \sim 10$ ) (Figs. 8 and 9). In contrast, at low temperatures (e.g. 5 and $15^{\circ} \mathrm{C}$ ) there was a lot of unreacted $\mathrm{NaOCl}$, and ethanol was added to quench the reaction. As a result, a lot of acidic compounds were formed. This led to the in situ formation of acetates which in turn caused a lowering of the reaction $\mathrm{pH}$ because of the buffering effect. It should be noted that the final reaction $\mathrm{pH}$ was adjusted to 7.0 at the end of reaction and before filtration. Saito and Isogai (2004) have also reported a similar correlation between $\mathrm{NaOH}$ consumption and the formation of carboxylate and aldehyde groups during TEMPO-mediated oxidation of cellulose cotton linters at $\mathrm{pH}$ 10.5.

\section{Oxidation of Pulp with US-TEMPO-System at pH 8.5-9.0}

Bragd et al. (2004) reported low $\mathrm{pH}$ optima, ca 8.0 for a bromide free 4acetamidoTEMPO/NaOCl oxidation system of carbohydrates. To find out whether similar $\mathrm{pH}$ optima would work for the 4-acetamidoTEMPO/ $\mathrm{NaBr} / \mathrm{NaOCl}$ system with native cellulose, pulp samples were subjected to US-TEMPO-system oxidation at $\mathrm{pH} 8.5$ 9.0. The results were compared with those obtained at $\mathrm{pH} 10.0$, as shown in Fig. 10. The pulp oxidized at $\mathrm{pH} 8.5-9.0$ had lower carboxyl content compared to that oxidized at $\mathrm{pH}$ 10.0. However, the DPv and yield after oxidation showed better selectivity at $\mathrm{pH} 8.5-9.0$ compared to $\mathrm{pH}$ 10.0. De Nooy et al. (1996) have also reported better selectivity (less fiber degradation due to $\beta$-elimination) at $\mathrm{pH} 9.2-9.7$ in a study on the oxidation of 
pullulan with TEMPO system. Despite the higher DPv and yield at $\mathrm{pH}$ 8.5-9.0, the oxidation of native cellulose with US-TEMPO or TEMPO system alone would be preferred at $\mathrm{pH} 10.0-10.2$, because the yields of the cellulose nanofibers are directly proportional to the carboxylate content in the oxidized pulp. This will be discussed in later sections.

\begin{tabular}{|c|c|}
\hline$\square$ COO- Oxn & Reaction conditions: \\
\hline$\square$ COO- Post-oxn & $\begin{array}{l}0.11 \mathrm{~m} \mathrm{~mol} / \mathrm{g} \text { cellulose; } \mathrm{NaBr}- \\
0.617 \mathrm{~m} \mathrm{~mol} / \mathrm{g} \text { cellulose; }\end{array}$ \\
\hline$\multimap$ Yield (\%) & $\mathrm{NaOCl}-3.75 \mathrm{~m} \mathrm{~mol} / \mathrm{g}$ \\
\hline$-x-D P v-o x n$ & $\begin{array}{l}\text { cellulose; Reaction time - } 90 \\
\text { min; Consistency - 1\%; }\end{array}$ \\
\hline$\rightarrow$ DPv Post-oxn & Temp. - $25^{\circ} \mathrm{C}$; US - $170 \mathrm{kHz}$ \\
\hline
\end{tabular}

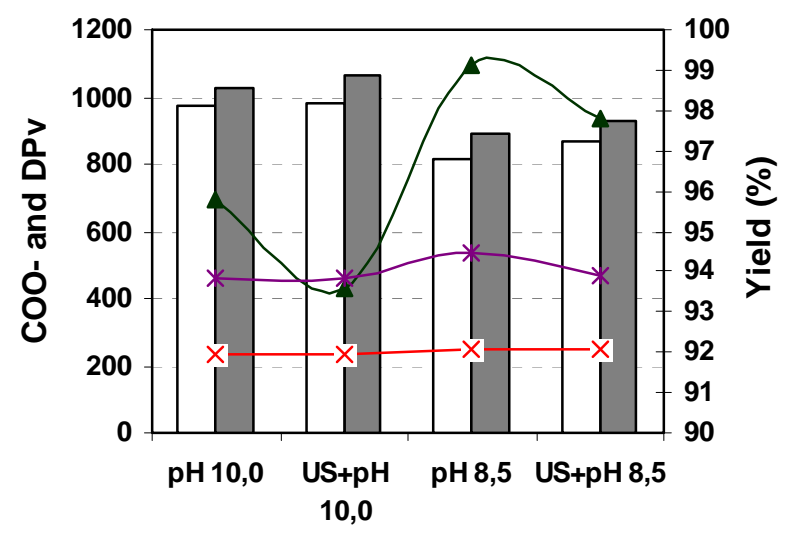

Fig. 10. Carboxyl groups, DPv, and yield versus reaction $\mathrm{pH}$ for the US-TEMPO and TEMPO oxidized pulp

\section{Effect of $\mathrm{NaBr}$}

Although catalytic amounts of $\mathrm{NaBr}$ and TEMPO are required in the TEMPO oxidation system, these two reagents have significant influence on the outcome of reaction if they are insufficiently dosed, for example yielding longer reaction times and lower desired functionalities. In the present work the effect of $\mathrm{NaBr}$ on the carboxyl groups, DPv, and yield of the pulp oxidized by the US-TEMPO-system was examined. The carboxyl group content and DPv before and after post-oxidation and yield after oxidation with US-TEMPO and TEMPO alone are presented as a function of $\mathrm{NaBr}$ charge and shown in Fig. 11. Under the given experimental conditions the amount of carboxyl groups increased, and $\mathrm{DPv}$ and yield decreased with increasing the amount of $\mathrm{NaBr}$. There was a clear-cut advantage in the case of the US-TEMPO-oxidation system in terms of carboxyl content. The carboxyl content of the samples oxidized in the USTEMPO-system was higher compared to TEMPO-system without US at all $\mathrm{NaBr}$ charges. At the maximum charge of $\mathrm{NaBr}(1.23 \mathrm{mmol} / \mathrm{g})$ a carboxyl content of 1350 $\mathrm{mmol} / \mathrm{kg}$ and about $88 \%$ yield were obtained in the US-TEMPO-system, while the TEMPO system gave a slightly lower carboxyl content of $1300 \mathrm{mmol} / \mathrm{kg}$ and a higher yield of $\sim 92 \%$. Analyses of the pulp after post-oxidation with $\mathrm{NaClO}_{2}$ showed similar 
trends for the $\mathrm{DPv}$, as previously discussed in the case of experiments conducted at different temperatures. This further showed that besides the loss in $\mathrm{DPv}$ during the oxidation with US-TEMPO or TEMPO-systems, the oxidized cellulose fibers were further depolymerized during the course of viscosity determination with CED solution. It seemed that the carboxyl content fell somewhat during the post-oxidation when the pulps contained high carboxyl content (e.g. oxidation at $24.69 \mathrm{mmol} \mathrm{NaBr} / 20 \mathrm{~g}$ pulp with US). The carboxyl content after post-oxidation was slightly inferior to that of the oxidized pulp in this case. However, the presence of carbonyl function was evident from the fact that the DPv after post-oxidation was almost doubled in all the cases (Fig. 11).

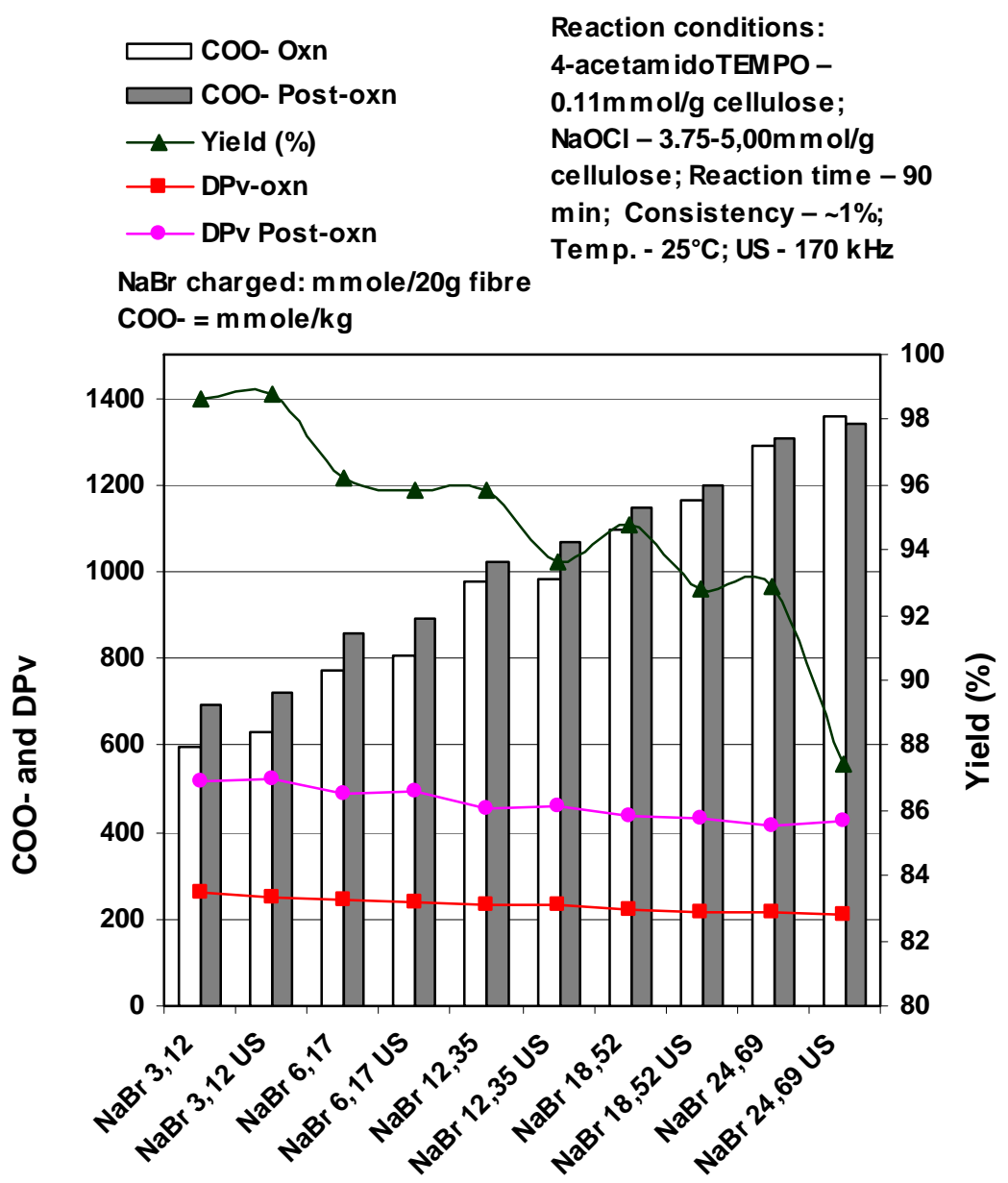

Fig. 11. Carboxyl groups, DPv, and yield versus $\mathrm{NaBr}$ charge on the US-TEMPO and TEMPO mediated oxidation of pulp. The numbers associated with $\mathrm{NaBr}$ on the $\mathrm{X}$-axis indicates the dose of $\mathrm{NaBr}(\mathrm{mmol} / 20 \mathrm{~g}$ pulp) applied with and without US.

de Nooy et al. (1995) found a linear relationship between the rate of oxidation of methyl $\alpha$-D-glucopyranoside, and the concentration of TEMPO and $\mathrm{NaBr}$. It was also shown that $\mathrm{OBr}^{-} / \mathrm{HOBr}$ is more reactive oxidant than $\mathrm{OCl}^{-}$, and that in the absence of $\mathrm{NaBr}$ the reaction rate was decreased significantly (de Nooy et al. 1995). Same reaction rates can be obtained by decreasing the concentration of TEMPO, and increasing the concentration of $\mathrm{NaBr}$ (Anelli et al. 1987; de Nooy et al. 1995). The finding of this study 
was in agreement with the results of de Nooy et al.; however, a detailed mechanism to explain this effect is unknown. An increased number of redox cycles at higher concentrations of $\mathrm{Br}^{-}$(or TEMPO) in the presence of excess of $\mathrm{NaOCl}$ (which is normally the case in the TEMPO-mediated reaction) may be a possible explanation. This would mean that the selection of the amount of $\mathrm{NaBr}$ in the US-TEMPO- and TEMPOoxidation system can be optimized according to the desired target properties (e.g. carboxyls content, DPv and yield, etc.).

\section{Production of Nanocellulose}

Cellulose nanofibers were prepared from samples oxidized with US-TEMPO and TEMPO-system alone. These oxidized pulps contained different levels of carboxyl content and were disintegrated by mechanical treatment. The nanocelluloses obtained were observed under Transmission Electron Microscope (TEM) to verify their nano-size structures. A TEM micrograph of the cellulose nanofibers is shown in Fig. 12.

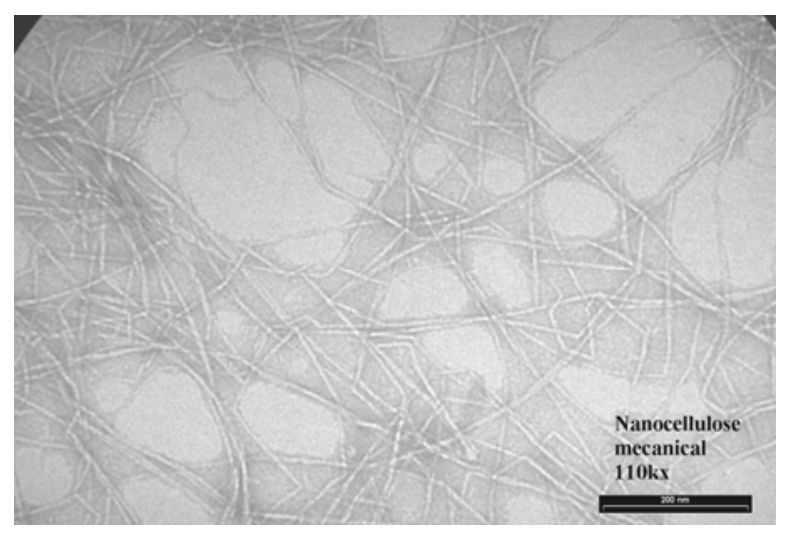

Fig. 12. TEM micrograph of the cellulose nanofibers prepared by mechanical treatment of the pulp oxidized with TEMPO-system

The TEM micrograph shows a number of the cellulose nanofibers with apparent kinks in them. The diameters of the individual nanofibers were measured, and were found to be in the range of 3 to $6 \mathrm{~nm}$ with varying length (not measured). The yield of the nanocellulose was quantified gravimetrically, as described in the experimental section. The yield of nanocellulose as a function of carboxyl content is presented in Fig. 13, which shows that the yield of nanocellulose increased with increasing carboxyl content. There was a clear correlation between the yield of cellulose nanofibers and carboxyl content. It was also found that at a given carboxyl content the US-TEMPO-system gave higher nanocellulose yield compared to TEMPO-system without US. For example, at a carboxyl content of ca. $1000 \mathrm{mmol} / \mathrm{kg}$ the US-TEMPO-system yielded about $10 \%$ more nanocellulose than the TEMPO alone did. However, the difference narrowed down when the carboxyl content reached $1100 \mathrm{mmol} / \mathrm{kg}$, as revealed in Fig. 13. 


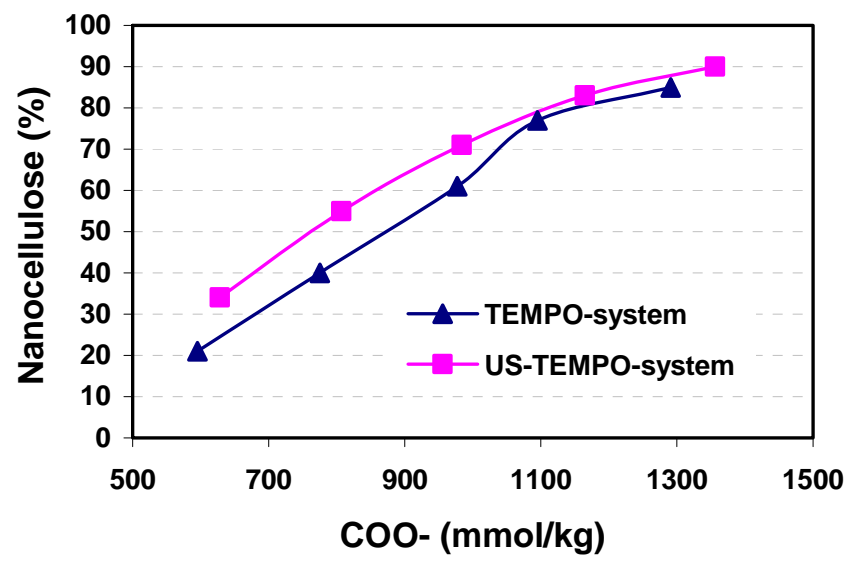

Fig. 13. Nanocellulose versus carboxyls content

The fact that the US-TEMPO-system produced higher carboxyl content and a great yield of nanocellulose in comparison to the usual TEMPO system could be attributed to the physical effects of the US treatment on the cellulose polymer chains. According to Suslick and Price (1999) there exist four physical effects responsible for the high-energy phenomena of the ultrasonic cavitation in liquid-solid systems. They are: (1) improvement of mass transport from turbulent mixing and acoustic streaming, (2) the generation of surface damage at liquid-solid interfaces by shock waves and microjets, (3) the generation of high velocity interparticle collisions in slurries, and (4) the fragmentation of friable solids to increase surface area. As we have mentioned earlier, the US treatment alone did not give any increase in the carboxyl content (Table 1), so the above mentioned phenomena could rightly be applicable for explaining the effects observed with cellulosic fibers. The collapse of cavitation bubbles in the reaction medium with the presence of oxidants facilitated the access of the reactive species to the reaction site (turbulent mixing and mass transfer), C6 hydroxyls in this case, with a greater ease, increasing the reaction rate and, consequently, increasing the carboxyl content. Meanwhile, the simultaneous damage to the fiber surface caused by the shockwaves and microjets facilitated the separation of nanofibers by mechanical treatment.

The results in Table 1 were obtained with ultrasound alone without the oxidants and did not represent the same chemical environment as the oxidations with TEMPO systems. Whether the oxidation of cellulose with the TEMPO-system in the presence of ultrasound will still be regioselective at $\mathrm{C} 6$ is not known. Hydroxyl radicals generated by sonolysis of water in the presence of $\mathrm{TEMPO} / \mathrm{NaBr} / \mathrm{NaOCl}$ may cause a possible oxidation of the $\mathrm{C} 2$ and $\mathrm{C} 3$ hydroxyls. The pulps oxidized with TEMPO- and USTEMPO-system were subjected to ${ }^{13} \mathrm{C}$ NMR analysis to confirm the presence of any possible $\mathrm{C} 2$ and $\mathrm{C} 3$ carbonyls or carboxyls. The ${ }^{13} \mathrm{C}$ NMR spectra of the reference, TEMPO- and US-TEMPO-system oxidized pulps are shown in Fig. 14.

Besides the resonance peaks for C1-C6 carbons (usually observed in ${ }^{13} \mathrm{C}$ NMR of cellulose) in all the samples a peak at 177 ppm for the C6 carboxyls was obtained in the case of pulps oxidized with TEMPO- and US-TEMPO-systems. However, no peaks for the carbonyl carbons of ketones (200-210 ppm) which may form at C2 or C3 (Isogai and 
Kato 1998) by the US-TEMPO or TEMPO-mediated oxidation were detected. Another observation is that the resonance peaks at $177 \mathrm{ppm}$ were very small despite a carboxyl content of about $1000 \mathrm{mmol} / \mathrm{kg}$ on dry pulp. Therefore, any small contribution due to the $\mathrm{C} 2$ or $\mathrm{C} 3$ carboxyls was either not present or beyond the detection limit of the NMR analysis in this case. Another observation is that there was no additional ${ }^{13} \mathrm{C}$ NMR peak in the samples oxidized with US-TEMPO-system compared to the TEMPO-system. This confirms our assumption that, like TEMPO-system, the oxidation with US-TEMPOsystem regioselectively occurs at C6 primary hydroxyl groups.

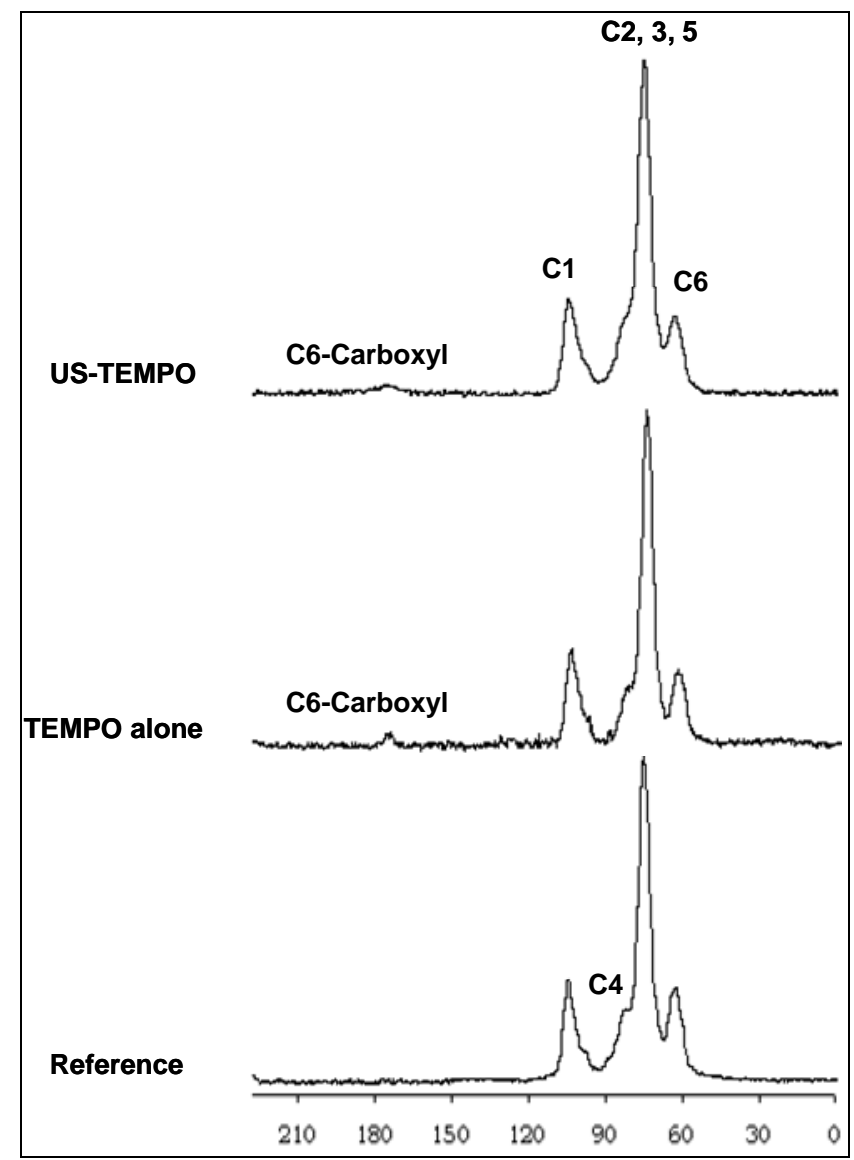

Fig. 14. NMR spectra of the reference and TEMPO- and US-TEMPO-system oxidized pulps

Compared to TEMPO alone, the US-TEMPO-system gave lower yield for the oxidized cellulose when the pulps were oxidized to high levels of carboxyl content. This nature needs further investigation, and experiments are being conducted to analyze the inherent pulp constituents before and after US-TEMPO oxidation. This will allow us to better understand the composition of the nanocellulose fraction and the fraction that remains unchanged after mechanical treatment. It is known that the bleached hardwood kraft pulp still contains at least $10-15 \%$ of hemicelluloses, which are amorphous in nature. The loss of hemicelluloses during the US-TEMPO oxidation could be one possible reason for the yield loss. As the oxidation of the cellulose proceeds, the interlinked hemicellulose components could be easily accessible to the oxidants and 
consequently, could be eliminated by dissolution. The analysis of soluble fraction after US-TEMPO oxidation is also envisaged.

\section{CONCLUSIONS}

1. An ultrasound-assisted TEMPO-system can facilitate the oxidation of native cellulose for the production of nanocellulose. This system gave a 10 to $15 \%$ increase in carboxyl content and 10\% augmentation in nanocellulose yield under optimized conditions.

2. Reaction temperature and $\mathrm{pH}$ have significant affect on the properties of oxidized pulp. To obtain acceptable carboxyl content, yield and DPv of the oxidized pulps, the following conditions may be employed for the US-TEMPO-system: $\mathrm{pH} 10.0$ to 10.5 and temperature $25^{\circ} \mathrm{C}$.

3. Measurement of $\mathrm{NaOH}$ consumption at regular intervals and end $\mathrm{pH}$ after the termination of reaction with ethanol can offer valuable information on the status of the US-TEMPO- oxidation system and possible outcomes.

4. The dosage of $\mathrm{NaBr}$ plays a crucial role in oxidation with or without US treatment in terms of carboxyl content of the oxidized pulp; it can be optimized to obtain the desired properties.

5. From the NMR analysis data it can be concluded that like TEMPO-system, oxidation with US-TEMPO-system is also regioselective, and occurs mainly at C6 primary hydroxyl groups.

\section{ACKNOWLEDGMENTS}

The authors are grateful for the financial support from the Natural Sciences and Engineering Research Council of Canada. The authors would like to thank Mr. Michel Paquin for the technical support offered during the execution of the experiments, and $\mathrm{Mr}$. Steve Mayer of Ultrasonic Power Corporation for providing the ultrasonic bath.

\section{REFERENCES CITED}

Anelli, P. L., Biffi, C., Montanari, F., and Quici, S. (1987). "Fast and selective oxidation of primary alcohols to aldehydes or to carboxylic acids and of secondary alcohols to ketones mediated by oxoammonium salts under two-phase conditions," The Journal of Organic Chemistry 52(12), 2559-2562.

Atalla, R. H. (1987). "Structures of Cellulose," In: The Structures of Cellulose, American Chemical Society, 1-14.

Besemer, A. C. (1993). "The bromide-catalyzed hypochlorite oxidation of starch and inulin," Delft University of Technology, The Netherlands.

Bragd, P. L., van Bekkum, H., and Besemer, A. C. (2004). "TEMPO-mediated oxidation of polysaccharides: Survey of methods and applications: Catalytic conversion of 
renewables," Guest Editors: van Bekkum, H., and Gallezot, P., Top. in Catalysis 27, 49-66.

Brown, R. (2010). "Forest products industry technology roadmap. Section 2: The forest products industry." Spoonsored by: Agenda 2020 Technology, IPST-Georgia Institute of Technology, American Forest and paper Association and U.S. Department of energy, April 2010.

Calvini, P., Conio, G., Lorenzoni, M., and Pedemonte, E. (2004). "Viscometric determination of dialdehyde content in periodate oxycellulose. Part I. Methodology," Cellulose 11(1), 99-107.

Chandra, S., and Gratzl, J. S. "Kinetics of carbohydrate and lignin degradation and formation of carbonyl and carboxyl groups in low consistency ozonation of softwood pulps," International Pulp Bleaching Conference, Quebec city, pp. 27-30.

Cherubini, F. (2010). "The biorefinery concept: Using biomass instead of oil for producing energy and chemicals," Energy Conversion and Management 51(7), 14121421.

Chirat, C., Lachenal, D., Coste, C., and Zumbrunn, J.P. "Effect of ozone on cellulose pulp," International Symposium on Wood and Pulping Chemistry pp. 368-378.

de Nooy, A. E. J., Besemer, A. C., and Van Bekkum, H. (1995). "Highly selective nitroxyl radical-mediated oxidation of primary alcohol groups in water-soluble glucans," Carbohydrate Research 269(1), 89-98.

de Nooy, A. E. J., Besemer, A. C., van Bekkum, H., van Dijk, J. A. P. P., and Smit, J. A. M. (1996). "Tempo-mediated oxidation of pullulan and influence of ionic strength and linear charge density on the dimensions of the obtained polyelectrolyte chains," Macromolecules 29(20), 6541-6547.

de Rodriguez, N. L. G., Thielemans, W., and Dufresne, A. (2006). "Sisal cellulose whiskers reinforced polyvinyl acetate nanocomposites," Cellulose 13(3), 261-270.

Du Manoir, J. R. (1980). "Mechanistic aspects of pulp viscosity loss during chlorination," CPPA Trans. Tech. Sect. 6(3), TR81-TR84.

Godsay, M. P., and Pearce, E. M. (1984). "Physico-chemical properties of ozone oxidized kraft pulps," Tappi Oxygen Delignification Symposium Notes, TAPPI Press, Atlanta, pp. 55-70.

Gratzl, J. (1987). "Degradation of carbohydrates and lignin by nonchlorine bleaching agents. Mechanisms as well as potential for stabilization," Papier 41(3), 120-130.

Gratzl, J. S. (1990). "Reactions of polysaccharides and lignins in bleaching with oxygen and related species," Tappi Oxygen Delignification Symposium Notes, TAPPI Press, Atlanta, pp. 1-21.

Habibi, Y., and Dufresne, A. (2008). "Highly filled bionanocomposites from functionalized polysaccharide nanocrystals," Biomacromolecules 9(7), 1974-1980.

Habibi, Y., Lucia, L. A., and Rojas, O. J. (2010). "Cellulose nanocrystals: Chemistry, self-assembly, and applications," Chemical Reviews 110(6), 3479-3500.

Henglein, A., and Kormann, C. (1985). "Scavenging of OH radicals produced in the sonolysis of water," International Journal of Radiation Biology 48(2), 251-258.

Henriksson, M., and Berglund, L. A. (2007). "Structure and properties of cellulose nanocomposite films containing melamine formaldehyde," Journal of Applied Polymer Science 106(4), 2817-2824. 
Hubbe, M. A., Rojas, O. J., Lucia, L. A., and Sain, M. (2008). "Cellulosic nanocomposites - A review," BioResources 3(3), 929-980.

Isogai, A., and Kato, Y. (1998). "Preparation of polyuronic acid from cellulose by tempomediated oxidation," Cellulose 5(3), 153-164.

Iwamoto, S., Nakagaito, A. N., and Yano, H. (2007). "Nano-fibrillation of pulp fibers for the processing of transparent nanocomposites," Applied Physics a-Materials Science \& Processing 89(2), 461-466.

Iwamoto, S., Nakagaito, A. N., Yano, H., and Nogi, M. (2005). "Optically transparent composites reinforced with plant fiber-based nanofibers," Applied Physics aMaterials Science \& Processing 81(6), CP8-1112.

Iwasaki, T., Lindberg, B., and Meier, H. (1962). "The effect of ultrasonic treatment on individual wood fibers," Sven. Papperstidn. 65, 795-816.

Janardhnan, S., and Sain, M. M. (2006). "Isolation of cellulose microfibrils - An enzymatic approach," BioResources 1(2), 176-188.

Johnson, P. E., Brun, E., MacKenzie, L. F., Withers, S. G., and McIntosh, L. P. (1999). "The cellulose-binding domains from Cellulomonas fimi [beta]-1,4-glucanase CenC bind nitroxide spin-labeled cellooligosaccharides in multiple orientations," Journal of Molecular Biology 287(3), 609-625.

Kamm, B., and Kamm, M. (2007). "Biorefineries - multi product processes," In: White Biotechnology, Ulber, R., and Sell, D. (eds.), Advances in Biochemical Engineering/Biotechnology, Springer Berlin, Heidelberg, 175-204.

Kardos, N., and Luche, J.-L. (2001). "Sonochemistry of carbohydrate compounds," Carbohydrate Research 332(2), 115-131.

Katz, S., Beatson, R. P., and Scallan, A. M. (1984). "The determination of strong and weak acidic groups in sulfite pulps," Sven. Papperstidn. 87(6), R48-R53.

Kitaoka, T., Isogai, A., and Onabe, F. (1999). "Chemical modification of pulp fibers by TEMPO-mediated oxidation," Nordic Pulp and Paper Research Journal 14(4), 279284.

Klemm, D., Heublein, B., Fink, H. P., and Bohn, A. (2005). "Cellulose: Fascinating biopolymer and sustainable raw material," Angewandte Chemie-International Edition 44(22), 3358-3393.

Leighton, T. G. (1994). The Acoustic Bubble, Academic Press, London, England.

Li, J. J. (2006). "TEMPO-mediated oxidation," In: Name Reactions, Springer Berlin Heidelberg, 589-591.

Luo, L., van der Voet, E., and Huppes, G. (2010). "Biorefining of lignocellulosic feedstock - Technical, economic and environmental considerations," Bioresource Technology 101(13), 5023-5032.

Manning, A. N., and Thompson, R. C. (2004). "De-inking of thick film UV-cured coatings using high intensity ultrasound," In: Surface Coatings International Part B: Coatings Transactions, p.22-26.

Nakagaito, A. N., and Yano, H. (2004). "The effect of morphological changes from pulp fiber towards nano-scale fibrillated cellulose on the mechanical properties of highstrength plant fiber based composites," Applied Physics A - Materials Science \& Processing 78(4), 547-552. 
Oksman, K., Mathew, A. P., Bondeson, D., and Kvien, I. (2006). "Manufacturing process of cellulose whiskers/polylactic acid nanocomposites," Composites Science and Technology 66(15), 2776-2784.

Paakko, M., Ankerfors, M., Kosonen, H., Nykanen, A., Ahola, S., Osterberg, M., Ruokolainen, J., Laine, J., Larsson, P. T., Ikkala, O., and Lindstrom, T. (2007). "Enzymatic hydrolysis combined with mechanical shearing and high-pressure homogenization for nanoscale cellulose fibrils and strong gels," Biomacromolecules, 8(6), 1934-1941.

Paakko, M., Vapaavuori, J., Silvennoinen, R., Kosonen, H., Ankerfors, M., Lindstrom, T., Berglund, L. A., and Ikkala, O. (2008). "Long and entangled native cellulose I nanofibers allow flexible aerogels and hierarchically porous templates for functionalities," Soft Matter 4(12), 2492-2499.

Rånby, B. G. (1952). "The cellulose micelles," Tappi 35(2), 53-58.

Saito, T., and Isogai, A. (2004). "TEMPO-mediated oxidation of native cellulose. The effect of oxidation conditions on chemical and crystal structures of the waterinsoluble fractions." Biomacromolecules, 5(5), 1983-1989.

Saito, T., and Isogai, A. (2005). "Ion-exchange behavior of carboxylate groups in fibrous cellulose oxidized by the TEMPO-mediated system." Carbohydrate Polymers, 61(2), 183-190.

Saito, T., Kimura, S., Nishiyama, Y., and Isogai, A. (2007). "Cellulose nanofibers prepared by TEMPO-mediated oxidation of native cellulose," Biomacromolecules 8(8), 2485-2491.

Saito, T., Nishiyama, Y., Putaux, J. L., Vignon, M., and Isogai, A. (2006a). "Homogeneous suspensions of individualized microfibrils from TEMPO-catalyzed oxidation of native cellulose," Biomacromolecules 7(6), 1687-1691.

Saito, T., Okita, Y., Nge, T. T., Sugiyama, J., and Isogai, A. (2006b). "TEMPO-mediated oxidation of native cellulose: Microscopic analysis of fibrous fractions in the oxidized products," Carbohydrate Polymers 65(4), 435-440.

Saito, T., Yanagisawa, M., and Isogai, A. (2005). "TEMPO-mediated oxidation of native cellulose: SEC-MALLS analysis of water-soluble and -insoluble fractions in the oxidized products," Cellulose 12(3), 305-315.

Samir, M., Alloin, F., and Dufresne, A. (2005). "Review of recent research into cellulosic whiskers, their properties and their application in nanocomposite field," Biomacromolecules 6(2), 612-626.

Samuelson, O. (1970). "Degradation of cellulose by different bleaching processes," Papier 24(10A), 671-678.

Sihtola, H., Kyrklund, B., Laamanen, L., and Palenius, I. (1963). "Comparison and conversion of viscosity and DP-values determined by different methods," Paperi ja Рuи 4, 225-232.

Stenstad, P., Andresen, M., Tanem, B. S., and Stenius, P. (2008). "Chemical surface modifications of microfibrillated cellulose," Cellulose 15(1), 35-45.

Suslick, K. S. (1990). "Sonochemistry," Science 247(4949), 1439-1445.

Suslick, K. S. (1995). "Applications of ultrasound to materials chemistry," MRS Bulletin 20(4), 29-34. 
Suslick, K. S., and Price, G. J. (1999). "Applications of ultrasound to materials chemistry," Annual Review of Materials Science 29(1), 295-326.

Taniguchi, T., and Okamura, K. (1998). "New films produced from microfibrillated natural fibres," Polymer International 47(3), 291-294.

Theander, O. (1975). "Carbohydrate reactions in oxygen-alkali delignification processes," In: First International Symposium on Delignification with Oxygen, Ozone and Peroxides, Raleigh, NC, p.41-57.

Thompson, R., and Manning, A. (2005). "A review of ultrasound and its applications in papermaking," Progress in Paper Recycling 14(2), 26-42.

Wang, B., and Sain, M. (2007). "Isolation of nanofibers from soybean source and their reinforcing capability on synthetic polymers," Composites Science and Technology 67(11-12), 2521-2527.

Wegner, T. H., and Jones, E. P. (2009). "A fundamental review of the relationships between nanotechnology and lignocellulosic biomass," In: The Nanoscience and Technology of Renewable Biomaterials, Lucia, L. A., and Rojas, O. J. (eds.), John Wiley \& Sons Ltd., 1-41.

Zhang, Y. Q., Fu, E. H., and Liang, J. H. (2008). "Effect of ultrasonic waves on the saccharification processes of lignocellulose," Chemical Engineering \& Technology 31(10), 1510-1515.

Article submitted: August 10, 2010; Peer review completed: Sept. 14, 2010; Revised version received: Nov. 18, 2010; Accepted: Nov. 22, 2010; Published: Nov. 24, 2010. 